\title{
Enttäuschung und Versagen
}

\section{Peter Marko}

Dr. med., Mitglied FMH

Die Leiterin unseres Hospizdienstes fragte mich, ob ich zu einer Frau schauen könne, die im Endstadium eines Lungenkrebses mit Metastasen ihre letzten Tage in einem Altersheim verbringe. Ich wusste nicht, wie viel Zeit ich für den Weg in die Gemeinde unweit von uns benötige, und so stand ich am nächsten Tag, etwas früher als angegeben, vor einem stattlichen, dreistöckigen, schönen, alten, solitären Haus und hatte genug Zeit zu sinnieren, wozu es früher dienen konnte. Gebaut noch in einer Zeit ohne Hotels und Fabriken, war es für ein Patrizierhaus zu schlicht und für eine Schule dieses Dorfes, falls es sie damals überhaupt schon gab, zu gross. Nachdem ich durch den alten, einfachen Eingang ins Haus kam, wurde ich nicht schlauer. Niemand war da, und so suchte ich alleine das Zimmer der Patientin. Ich ging neben vielen alten Türen mit den Namen der Bewohner dieser offensichtlich kleinen Räume, die als Schulklassen sicher unge- eignet waren. Im letzten Zimmer im obersten Stock sass die Frau auf dem Bettrand mit einer aufgesetzten Sauerstoffbrille. Im Vorraum summte der Apparat für die Anreicherung des Sauerstoffs. Sie hatte Besuch von einer Freundin, die sich aber bald verabschiedete.

Das Zimmer war ohne die warmen Täferwände, die ich in den Gemeinschaftsräumen im Erdgeschoss sah und in den anderen Zimmern vermutete. Schlicht und notdürftig war es eingerichtet: Ausser dem verstellbaren Bett und dem auch verstellbaren Tischchen, zwei Stühlen und einem Sessel guckte nur ein grosser Bildschirm aus der Ecke hervor. Ich hatte den Eindruck, dass alles, ausser dem Koffer am Boden, dem Altersheim gehörte. Ich sah keinen persönlichen Gegenstand, kein Bild, kein Foto. Bald kam der Pfleger, froh, dass er mich bei der Patientin entdeckte, und fragte, ob wir Lust auf Kaffee hätten. Er brachte nicht nur Kaffee, sondern auch Kuchen. Weder er aus einem Nachbar-

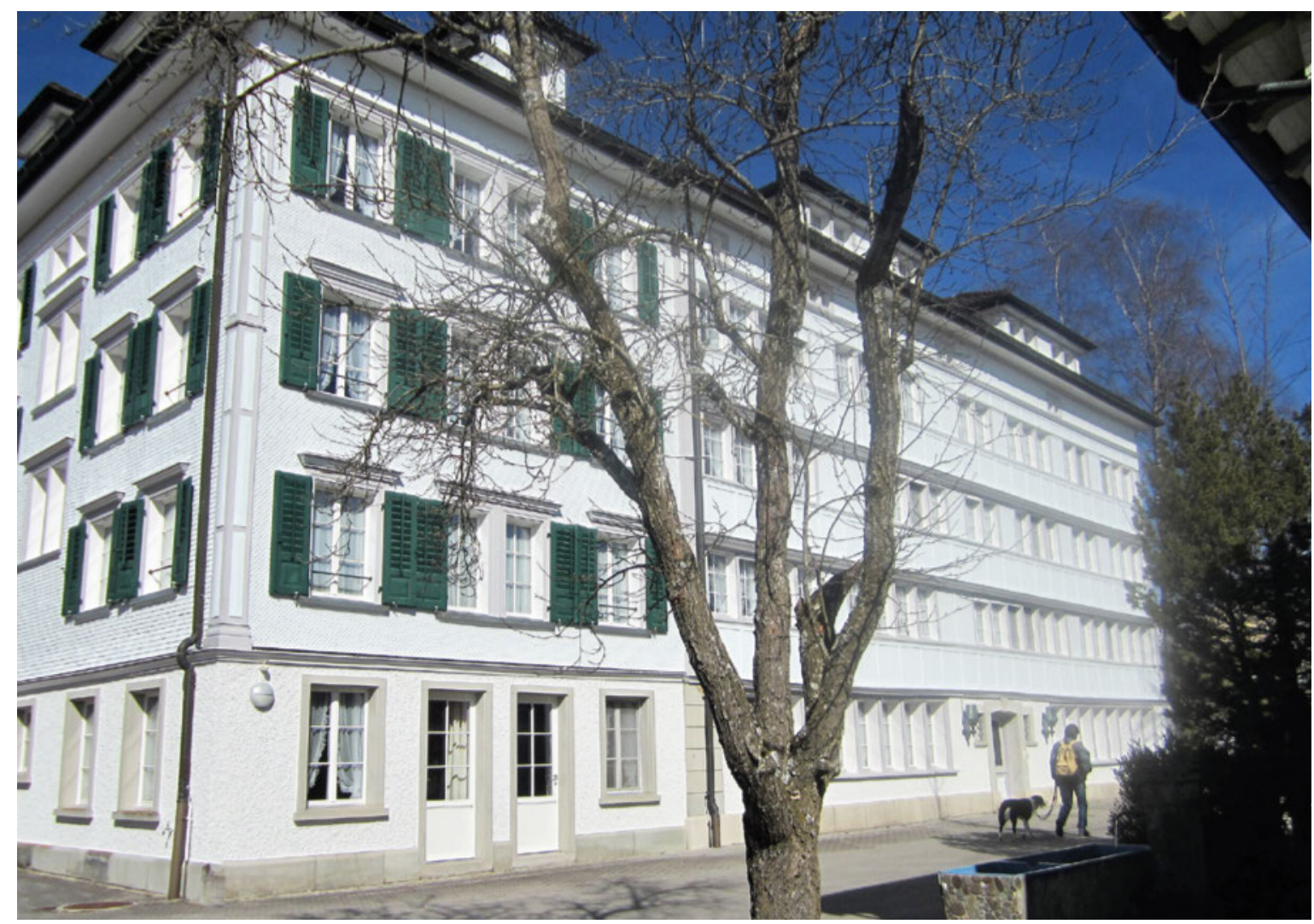

Ehemaliges Altersheim. 
land noch die Frau aus dem Dorf wussten, wozu das Haus einmal gebaut wurde. Wir hatten es gemütlich. Draussen war es kalt, die Sicht war schlecht, aber ich konnte mir vorstellen, dass der Blick aus dem Fenster schön war. Ja, sagte die Patientin, bei Föhn habe man den Säntis fast direkt vor der Nase. Ich bedauerte, dass ich nie dazu kam, von diesem Sehnsuchtsberg der Ostschweizer auf den Skiern runterzufahren. Sie sagte, sie hätte es mit ihrem verstorbenen Mann mehrmals getan. Wir berichteten über unsere Skierlebnisse und meinten, hie und da auf einer Piste oder im Sommer bei einer Wanderung hätten wir uns treffen können. Ich bekam immer mehr den Eindruck, die Frau und die Einrichtung des Zimmers passten irgendwie nicht zusammen. Nach einer Weile äusserte sie den Wunsch, das Zimmer zu verlassen. Sie rief den Pfleger, der sie in den Rollstuhl setzte, mit einer Sauerstoffflasche versorgte und mit einer Decke den Oberkörper einhüllte. Zuerst dachte ich, wir würden etwas auf dem Gang hin und her fahren, aber sie steuerte mich zum Lift, sie wollte nach draussen gehen. Ich meinte, sie sollte dann die Füsse besser schützen. Sie erwiderte, sie habe warme Füsse und nie kalt. Draussen an der frischen Luft zog sie aus der Tasche eine Zigarette und Streichhölzer und inhalierte mit Genuss den Rauch. Ich schob sie eine Weile nicht weit vor dem Haus hin und her, und bald nach der zweiten Zigarette kehrten wir ins Zimmer zurück. Gegen Ende meiner vorgesehenen Zeit kam eine andere Freundin mit dem Hund der Patientin, der mich freundlich beschnupperte und wie sie eine riesige Freude zeigte. Ich verabschiedete mich mit der Hoffnung, wieder zu ihr zu kommen. Beim Ausgang traf ich ein paar Pflegerinnen, dem Dialekt nach aus dem Dorf oder der Umgebung, aber sie konnten mir auch nicht sagen, was früher im Haus war.

Schneller als ich dachte, schon in vier Tagen, kehrte ich zu der Frau zurück, weil einer Kollegin etwas dazwischenkam. Die erste Freundin war wieder bei ihr, verabschiedete sich aber bald. Die Frau sah schlechter, eingefallener aus, die Füsse waren kalt und blau verfärbt. Sie war unruhig, ich musste ihr beim ständigen Aufsitzen, Abliegen, Drehen helfen. Wir bekamen den Kaffee, aber es war nicht mehr gemütlich. An einen Ausflug mit Zigarette war nicht zu denken. Sie seufzte und meinte, wenn nur das Ende käme. Ich fragte sie, ob sie Angst davor habe. Ruhig und überzeugend sagte sie: wieso, vor was? Sie läutete nach dem Pfleger und wollte etwas gegen Schmerzen haben, die vom rechten Unterbauch in den Oberschenkel ausstrahlten. Er sagte, dass sie vor nicht langer Zeit bereits Tropfen gegen Schmer- zen bekommen habe. Sie liess nicht nach, und so brachte er ihr die Tropfen wieder. Sie fiel in den Schlaf und erwachte erst, als die Freundin mit dem Hund kam. Die Begrüssung war weniger stürmisch als das letzte Mal. Ich dachte mir, der Tod steht schon bereit am oberen Ende des Bettes. Später erfuhr ich, dass man das Bett nicht wie im Märchen "Gevatter Tod» umdrehte, sondern die Patientin ins Spital verlegte. Dem Tod dauerte es vier Tage, bis er sie dort fand.

Warum musste er diesen Umweg machen? Deutete schon die schlichte Einrichtung des Zimmers darauf? Wollte sie sich dort nicht heimisch fühlen? Die Patientin schien bereit, den Tod zu treffen. Überlegte sie sich es doch noch? Waren die Pflegeleute sparsam und überfordert mit den Tropfen? Warum verschrieb der Arzt kein länger wirksames Medikament? Wollte eine der Freundinnen sie "noch nicht» verlieren? Starb sie im Spital doch ruhiger, leichter?

Beschäftigt mich diese Geschichte, weil dabei die Früchte unseres Einsatzes, den Menschen zu helfen, dort zu sterben, wo sie es sich wünschen, kurz vor der Erfüllung zunichte gemacht wurden? Jedenfalls möchte ich nicht, dass man meinen Willen vor dem Tod nicht beachtet. Oder reut es mich, dass die Patientin das Haus verliess, das mich an die heimeligen Altersheime erinnerte, in denen ich die Patienten nicht selten bis zum Tod betreute, oder sogar an das im Vergleich winzige Grosselternhaus, das ein paar Jahrzehnte weniger auf dem Buckel hatte als dieses Haus? Es wurde zwar weit weg ganz anderswo gebaut, aber die Wände wurden auch mit warmem dunkelbraunem Täfer belegt, und die ähnlichen Türen hatten ähnliche Schlösser wie hier.

Ich fragte das Gemeindeamt, zu welchem Zweck das Haus gebaut wurde. Erst nach mehreren Tagen schickte mir der offensichtlich an Geschichte interessierte Gemeindeammann einen langen Auszug aus einem Buch mit Bildern über die Gemeinde - von Anfang an diente es fast ein Jahrhundert als Waisenhaus für die ganze Umgebung. Damals brauchte man Waisenhäuser und nicht Altersheime, weil die Leute früher und schneller starben. Ob auch leichter und würdiger als in unserer Zeit?

Vor kurzem las ich in der Zeitung, das Haus sei nicht mehr zeitgemäss eingerichtet und werde in Wohnungen umgebaut. Die Zeiten ändern sich und wir mit ihnen - ein slowakisches Sprichwort.

Bildnachweis (C) Silvia Marko 